\title{
Rheological Properties of Compatible Blends of Acrylonitrile-Styrene Copolymer and Styrene-Maleic Anhydride Copolymer
}

\author{
Yuji AOKI \\ Yokkaichi Research and Development Department, \\ Mitsubishi Monsanto Chemical Co., Ltd., \\ Toho-cho, Yokkaichi, Mie 510, Japan
}

(Received January 17, 1984)

\begin{abstract}
KEY WORDS Compatible Blend / Melt Rheology / Free Volume / Viscosity / Steady State Compliance / Acrylonitrile-Styrene Copolymer / Styrene-Maleic Anhydride Copolymer /
\end{abstract}

The melt rheology of compatible polymer blends has been studied only very little, although many compatible systems have been found recently. Prest and Porter ${ }^{1}$ studied the viscoelastic properties of blends of polystyrene (PS) and poly(2,6-dimethyl phenylene oxide) (PPO) which are compatible, and found that glass transition temperature of the blend can be accurately predicted assuming the additivity of the free volumes of components. They also studied the compositional dependence of zero shear viscosity for the same systems. However, the measurements were limited to samples less than $50 \mathrm{wt} \%$ of PPO because of the high viscosity of PPO and thermal instability of both components. The viscoelastic properties of compatible blends over the entire region of the composition should also be studied.

In the present work, the dynamic viscoelastic properties of blends of acrylonitrile-styrene copolymer and styrene-maleic anhydride copolymer were studied near the glass transition and more elevated temperatures. Good compatibility of the blends was found on the basis of glass transition behavior. A detailed study was made of the dynamic viscoelastic properties of the blends in the molten state. Compositional dependences of shift factor, zero shear viscosity and steady state shear compliance of the blends are discussed.

\section{EXPERIMENTAL}

Styrene-maleic anhydride copolymer (SMA) used in the present work was commercially obtained in pellet-form (Dylark 332, Arco Polymers Inc.). The acrylonitrile-styrene copolymer (AS-15) was prepared at our laboratory by radical polymerization with di-tertbutyl peroxide as the initiator. The molecular characteristics of copolymers are given in Table I. The maleic anhydride content (MA \%) of SMA was measured on a coulometric titrator (Mitsubishi Chemical Industry Co., Model CT-01). Acrylonitrile content (AN\%) of AS-15 was measured by elementary analysis (Yanako, CHN Coder). The weight-average

Table I. Molecular characteristics of the samples

\begin{tabular}{ccccc}
\hline & \multicolumn{2}{c}{ Styrene content } & & \\
\cline { 2 - 3 } & $\mathrm{wt} \%$ & $\mathrm{~mol} \%$ & & $M_{w} / M_{n}$ \\
\hline SMA & 84.7 & 83.9 & $18.5 \times 10^{4}$ & 2.0 \\
AS-15 & 85.1 & 74.4 & $12.8 \times 10^{4}$ & 2.6 \\
\hline
\end{tabular}


molecular weight $\left(M_{w}\right)$ was determined by low-angle laser light scattering (Chromatix, KMX-6) and the polydispersity index $M_{w} / M_{n}$ by GPC (Waters, 150C ALC/GPC) in tetrahydrofuran.

SMA and AS-15 were blended with a Brabender Plastograph at $200^{\circ} \mathrm{C}$ for about 5 min. The blend composition was AS$15 / \mathrm{SMA}=100 / 0,75 / 25,50 / 50,25 / 75$, and $0 / 100$ by weight and all blends were transparent.

Dynamic mechanical measurements were made to test sample compatibility using a Viscoelastic Spectrometer (Iwamoto Seisakusho Co.) at a heating rate of about $1^{\circ} \mathrm{C} \mathrm{min}^{-1}$ and frequency of $20 \mathrm{~Hz}$, within a temperature range from 25 to $150^{\circ} \mathrm{C}$.

The real and imaginary parts of the complex shear modulus $G^{\prime}$ and $G^{\prime \prime}$ were measured with a concentric cylinder type rheometer (Thixotrometer, Iwamoto Seisakusho Co.) by changing the angular frequency $\omega$ in the range from $1.05 \times 10^{-2}$ to $4.2 \times 10^{\circ} \mathrm{s}^{-1}$ at temperatures from $140^{\circ} \mathrm{C}$ to $245^{\circ} \mathrm{C}$. The frequency dependences of $G^{\prime}$ and $G^{\prime \prime}$ at various temperatures were superimposed by shifting along the frequency axis by a factor $a_{\mathrm{T}}$.

\section{RESULTS AND DISCUSSION}

Figure 1 shows the temperature dispersions of the dynamic storage modulus $E^{\prime}$ and loss modulus $E^{\prime \prime}$ for the AS-15/SMA blends. The $E^{\prime \prime}$ curve of each blend has only a single peak corresponding to the glass transition temperature. The temperature at which a peak on the $E^{\prime \prime}$ curve occurs shifts to a higher temperature with increasing SMA content. The $E^{\prime \prime}$ curve peaks are as high and sharp as those of the component copolymers. These findings indicate AS-15 and SMA to be compatible on the molecular level.

The viscoelastic behavior of the AS-15/SMA blends was examined in the molten state. Figure 2 shows the temperature dependence of the shift factor $a_{\mathrm{T}}$ for the blends. The reference

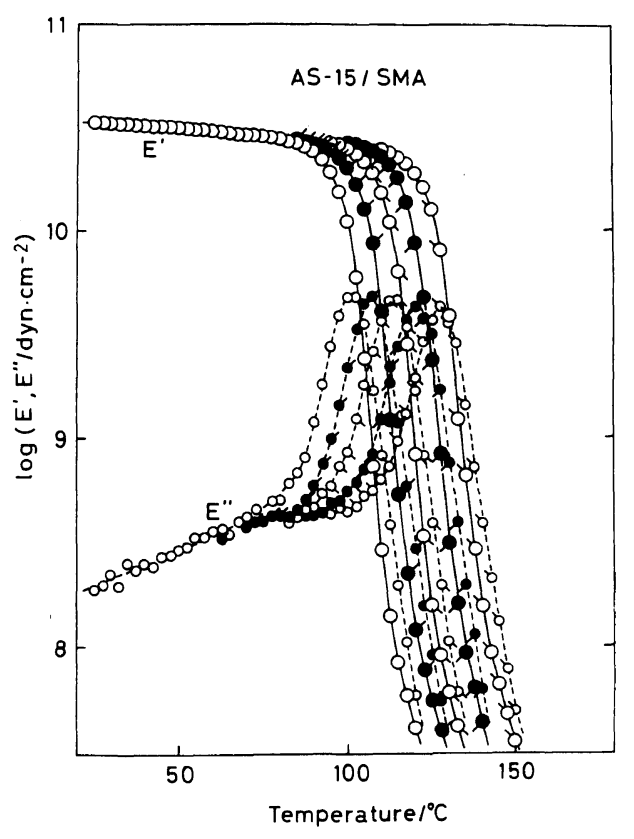

Figure 1. Temperature dispersions of dynamic storage $\left(E^{\prime}\right)$ and loss $\left(E^{\prime \prime}\right)$ moduli at $20 \mathrm{~Hz}$ for the AS-15/SMA blends: (O), 100/0; ( $\checkmark$ ), 75/25; (○), 50/50; ( $\odot)$, 25/75; ( O), 0/100.

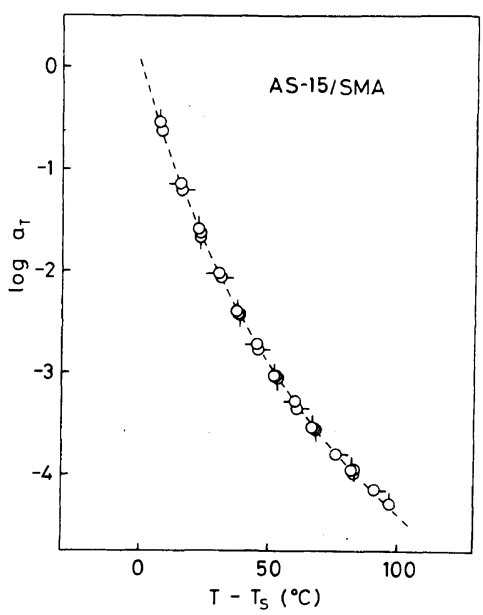

Figure 2. Temperature dependence of the shift factors $a_{\mathrm{T}}$ for the AS-15/SMA blends. The reference temperatures were $133,139,147,155$, and $162^{\circ} \mathrm{C}$ for AS$15 / \mathrm{SMA}=100 / 0,75 / 25,50 / 50,25 / 75$ and $0 / 100$, respectively. The dotted line denotes the WLF equation: (○), 100/0; (○-), 75/25; (९), 50/50, (-○), 25/75; (○), $0 / 100$. 
temperature $T_{\mathrm{s}}$ was chosen at 133, 139, 147, 155 , and $162^{\circ} \mathrm{C}$ for $\mathrm{AS}-15 / \mathrm{SMA}=100 / 0$, $75 / 25,50 / 50,25 / 75$, and $0 / 100$. In this figure, the dotted line denotes the WLF equation, ${ }^{2}$

$$
\log a_{\mathrm{T}}=-c_{1}\left(T-T_{\mathrm{s}}\right) /\left(c_{2}+T-T_{\mathrm{s}}\right)
$$

where $c_{1}=8.86$ and $c_{2}=101.6$. All curves coincide with the WLF equation. Figure 3 shows the dependence of $T_{\mathrm{s}}$ on composition. The $T_{\mathrm{s}}$ of the blends was found to be a linear function of mole fraction $x$ of SMA. Accordingly, $T_{\mathrm{s}}^{\text {blend }}$ is given by

$$
T_{\mathrm{s}}^{\text {blend }}=(1-x) T_{\mathrm{s}}^{\mathrm{AS}}+x T_{\mathrm{s}}^{\mathrm{SMA}}
$$

where $T_{\mathrm{s}}^{\mathrm{AS}}$ is the $T_{\mathrm{s}}$ of AS-15 and $T_{\mathrm{s}}^{\mathrm{SMA}}$ that of SMA.The $T_{\mathrm{s}}$ for many polymers was found to be $50^{\circ} \mathrm{C}$ higher than the glass transition temperature $T_{\mathrm{g}}$. This explains why the glass transition temperature of blends is a linear function of the mole fraction of SMA.

The above data can be understood in terms of the free volume concept and additivity of the free volumes of the component copolymers. The free volume of a polymer, $f$, at a temperature $T$ is given by

$$
f=f_{0}+\alpha\left(T-T_{\mathrm{s}}\right)
$$

where $f_{0}$ is the free volume at $T_{\mathrm{s}}$ and $\alpha$, the temperature coefficient of that free volume.

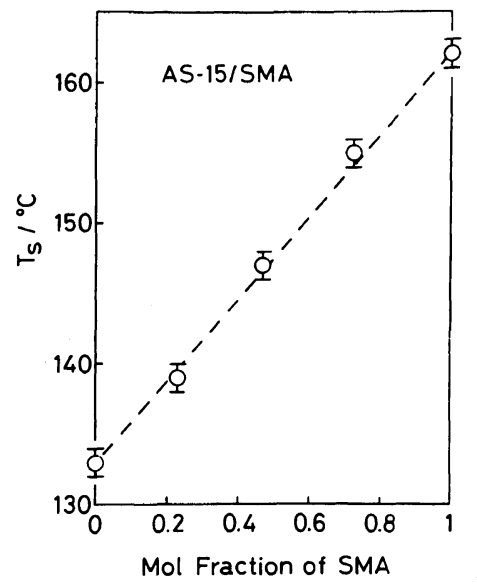

Figure 3. Compositional dependence of the reference temperature $T_{\mathrm{s}}$ for the AS-15/SMA blends.
According to the Doolittle equation ${ }^{3}$ which describes the relationship between the viscosity of a system and the temperature dependence of free volume, $f_{0}$ is $B / 2.303 c_{1}$ and $\alpha$ is $f_{0} / c_{2}$, where $B$ is a constant of the order of one. The results in Figure 2 indicate both $c_{1}$ and $c_{2}$ to be constant at each $T_{\mathrm{s}}$ of the component copolymers and blends. Accordingly, $f_{0}$ and $\alpha$ are also constant at each $T_{\mathrm{s}}$ independent of composition. The free volume of blends, $f^{\text {blend }}$, is given by eq 4 .

$$
f^{\text {blend }}=f_{0}+\alpha\left(T-T_{\mathrm{s}}^{\text {blend }}\right)
$$

Putting eq 2 into eq 4 ,

$$
\begin{aligned}
f^{\text {blend }} & =f_{0}+\alpha\left\{T-(1-x) T_{\mathrm{s}}^{\mathrm{AS}}-x T_{\mathrm{s}}^{\mathrm{SMA}}\right\} \\
& =(1-x) f^{\mathrm{AS}}+x f^{\mathrm{SMA}}
\end{aligned}
$$

Equation 5 indicates that the additivity of the free volumes of the component copolymers is applicable for AS-15/SMA system.

Figures 4 and 5 show the master curves of $G^{\prime}$ and $G^{\prime \prime}$ for the AS-15/SMA blends and the component copolymers, respectively, as a function of the reduced frequency $\omega a_{\mathrm{T}}$. At high frequencies, the heights of $G^{\prime}$ and $G^{\prime \prime}$ are constant and independent of the blend ratio. At low frequencies, $G^{\prime \prime}$ is proportional to $\omega a_{\mathrm{T}}$ for each sample. This is a Newtonian flow region where the dynamic viscosity $\eta^{\prime}=G^{\prime \prime} / \omega$

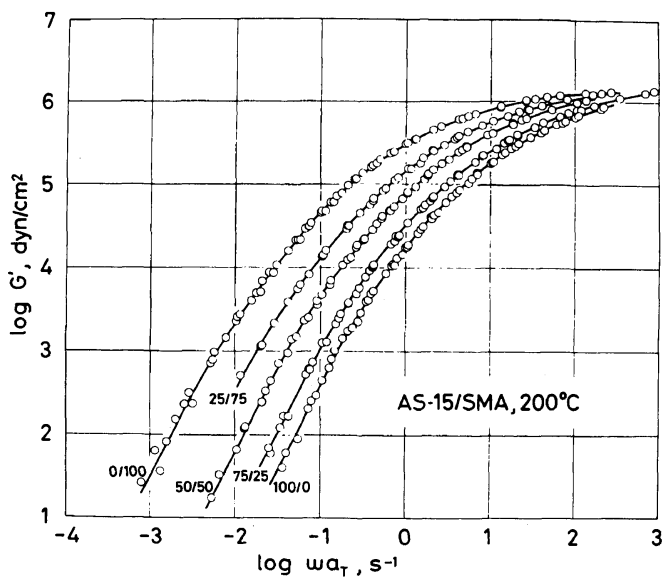

Figure 4. Master curves of the storage shear modulus $G^{\prime}$ reduced to $200^{\circ} \mathrm{C}$ for the AS-15/SMA blends. 


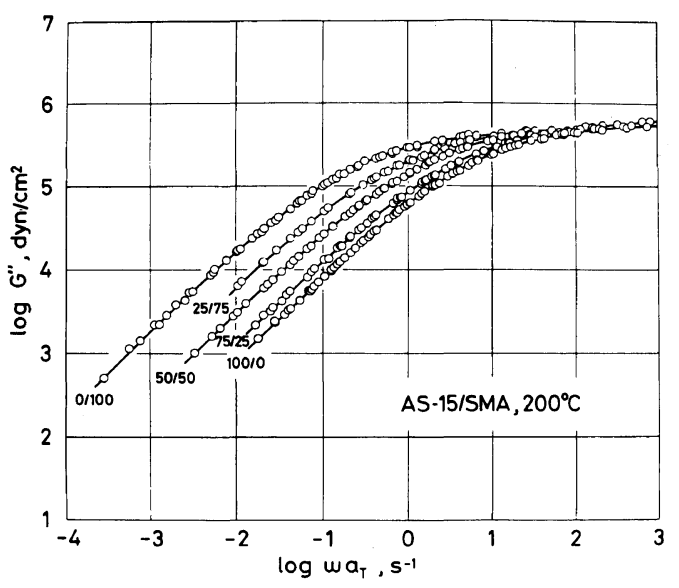

Figure 5. Master curves of the loss shear modulus $G^{\prime \prime}$ reduced to $200^{\circ} \mathrm{C}$ for the AS-15/SMA blends.

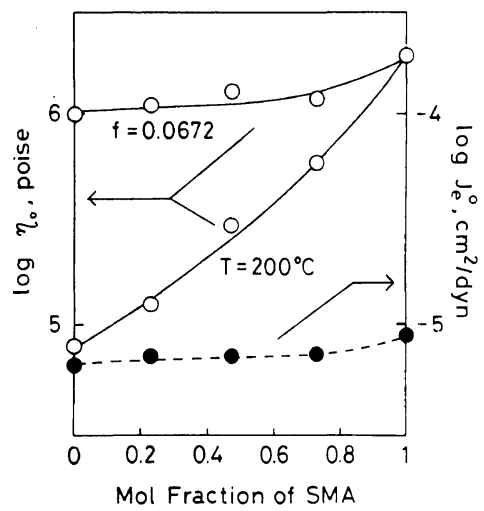

Figure 6. Compositional dependence of the zero shear viscosity $\eta_{0}$ and steady state compliance $J_{\mathrm{e}}{ }^{0}$ of the AS15/SMA blends as a function of the SMA mole fraction.

is independent of frequency. The slope of $\log G^{\prime}$ curve plotted against $\log \omega a_{\mathrm{T}}$ for each sample is 2. Therefore, the characteristic parameters in the terminal zone, zero shear viscosity $\eta_{0}=\lim _{\omega \rightarrow 0}\left(G^{\prime \prime} / \omega\right)$ and steady state compliance $J_{\mathrm{e}}^{0}=\lim _{\omega \rightarrow 0}\left(G^{\prime} / \omega^{2} \eta_{0}{ }^{2}\right)$, can be calculated from these data.

Figure 6 shows $\eta_{0}$ and $J_{\mathrm{e}}{ }^{0} v s$. the mole fraction of SMA plots. At a constant temperature of $200^{\circ} \mathrm{C}, \eta_{0}$ increases with an increase in the mole fraction of SMA. However, when $f=$ 0.0672 , the value of SMA at $200^{\circ} \mathrm{C}, \eta_{0}$ is almost independent of composition. $J_{\mathrm{e}}{ }^{0}$ also shows hardly any dependence on the blend ratio.

The zero shear viscosity of polymer melts at equal free volumes and is given by

$$
\eta_{0}=\eta_{0}\left(M_{\mathrm{c}}\right)\left(M_{w} / M_{\mathrm{c}}\right)^{3.5} \quad M_{w}>M_{\mathrm{c}}
$$

where $M_{\mathrm{c}}$ is the critical molecular weight. If $\eta_{0}\left(M_{\mathrm{c}}\right)$ of $\mathrm{AS}-15$ is equal to that of SMA, we obtain the relation,

$$
\eta_{0}{ }^{\mathrm{AS}} / \eta_{0}{ }^{\mathrm{SMA}}=\left\{\left(M_{w}{ }^{\mathrm{AS}} / M_{\mathrm{c}}{ }^{\mathrm{AS}}\right) /\left(M_{w}{ }^{\mathrm{SMA}} / M_{\mathrm{c}}{ }^{\mathrm{SMA}}\right)\right\}^{3.5}
$$

Putting experimental values into eq 7 ,

$$
M_{\mathrm{c}}^{\mathrm{SMA}} / M_{\mathrm{c}}{ }^{\mathrm{AS}}=1.3
$$

The reason why $M_{\mathrm{c}}{ }^{\mathrm{SMA}}$ is larger than $M_{\mathrm{c}}{ }^{\mathrm{AS}}$ is considered to be that the $\mathrm{C}-\mathrm{C}$ bonds of the MA unit in SMA chains cannot rotate freely. Equation 8 indicates the number of entanglement couplings in an SMA chain to be nearly equal to that in an AS-15 chain, although the weight-average molecular weight of AS-15 is lower than that of SMA.

Since SMA and AS-15 are compatible on the molecular level, the blends should have three kinds of entanglement couplings involving the molecular chains of SMA-SMA, SMA-AS and AS-AS. The entanglement couplings between SMA and AS-15 chains in the blends are considered to interact in the same as those of the SMA and SMA chains or AS15 and AS- 15 chains in each component copolymer. The number of entanglement couplings in an SMA chain is nearly equal to that in an AS-15 chain. The number of entanglement couplings per chain in the blends is thus almost equal to that in the component copolymers. This may possibly explain why both $\eta_{0}$ and $J_{\mathrm{e}}{ }^{0}$ are almost independent of the blending ratio.

The following conclusions may be drawn. AS-15/SMA blends act as a one phase system, as shown by rheological measurements. Only the free volumes of the blends change with the blending ratio. $\eta_{0}$ and $J_{\mathrm{e}}{ }^{0}$ depend on the 
Rheology of Compatible Polymer Blends

number of entanglement couplings, rather than molecular weight.

\section{REFERENCES}

1. W. M. Prest, Jr. and R. S. Porter, J. Polym. Sci., A-2,
10, 1639 (1972)

2. M. L. Williams, R. F. Landel, and J. D. Ferry, J. Am. Chem. Soc., 77, 3701 (1955).

3. A. K. Doolittle, J. Appl. Phys., 22, 1471 (1951). 